DOI: $\underline{10.7242 / 2658-705 X / 2020.1 .7}$

УДК 616-71; 616-006.6; 535.4; 535-15

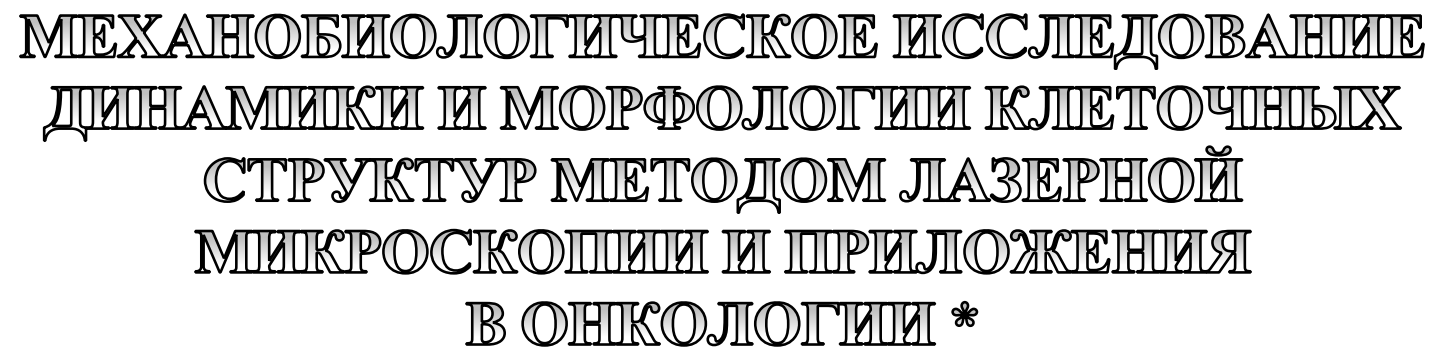

О.Б. Наймарк, Институт механики сплошных сред УрО РАН

В.В. Гришко, Институт технической химии УрО РАН

Ю.В. Баяндин, Институт механики сплошных сред УрО РАН

А.С. Никитюк, Институт механики сплошных сред УрО РАН

Исследования посвящены экспериментальному и теоретическому обоснованию использования механобиологических характеристик клеток как фенотипических маркеров онкологических патологий. В развитие подходов, связанных с изучением механического состояния клеток в «норме» и при эволюции опухолей, проведен сравнительный анализ нелинейной динамики клеточных структур на основе оригинальных данных по динамике «фазовых толщин» клеток, получаемых методом когерентной фазовой микроскопии. Результаты экспериментальных исследований обобщены на основе эпигенетических моделей, отражающих механобиологические особенности клеточных и тканевых структур при развитии рака.

Ключевые слова: механобиология клеток, когерентная фазовая микроскопия, открытые комплексы, нелинейная динамика, морфометрия, монои мультифрактальность.

\section{Введение}

В настоящее время существенное внимание уделяется изучению механического поведения клеток и тканей при развитии онкологических заболеваний, в ходе которых установлены качественные различия в механических свойствах «нормальных» и раковых клеток, проявляющиеся на уровне тканей, в том числе при развитии опухолей. Изменение механобиологических реакций клеток и тканей потенциально отражает степень «поврежденности» биологической системы и может использоваться в качестве нового диагностического инструмента, дополняющего традиционные биохимические и молекулярно-генетические методы, используемые в клинической практике. Перспектива использования результатов механобиологических исследований для классификации заболеваний, связанных с механическими изменениями клеток и тканей, предполагает обоснование методов сбора, обработки данных и их анализа с учетом выраженных нелинейных свойств неравновесной механобиологической системы. Целью исследования явля-

* Работа выполнена при поддержке Российского фонда фундаментальных исследований. Грант № 16-41-590235. 
лось изучение механобиологических реакций клеток методами когерентной фазовой микроскопии с последующим выделением «значимых» коллективных степеней свободы, определяющих динамическую устойчивость биологической системы и ее качественное изменение с ростом «поврежденности», что в сочетании с молекулярно-генетическими (эпигенетическими) подходами является актуальным направлением по объективизации признаков онкологических заболеваний. Использование результатов трансдисциплинарных исследований в области механобиологии клеток и тканей может являться одним из наиболее эффективных и физически обоснованных методов ранней диагностики, когда другие симптомы не позволяют провести количественное определение фенотипа и стадийности развития онкологического заболевания. На основе созданных программных комплексов, реализующих выделение пространственно-временных сингулярных мод различной природы (конечноамплитудных возмущений, характеризующих кинетику поврежденности клетки), обоснована методология обработки данных когерентной фазовой микроскопии для количественной дифференциации клеток «в норме» и раковых клеток, основанная на вычислении инвариантов динамического поведения системы.

\section{Механобиология клеточных структур}

Развитие рака связывается с генетическими мутациями и многомасштабными механобиологическими процессами, которые могут способствовать выходу клеток из гомеостатического тканевого контроля. Объектом механобиологии является изучение физических факторов, вовлеченных в процесс механотрансдукции, то есть способности клеток ощущать силовое и физическое окружение посредством их цитоскелетной организации, а также изменять свою форму и подвижность. Концепции механобиологии применяются для изучения физических факторов, вовлеченных в процесс механотрансдукции, как реакционной способности биологической системы на силовые и физические поля на масштабах клеток и тканей. При нормальных условиях клеточный цитоскелет реализует естественную клеточную динамику, определяющую фенотип клеток и ее функции, обусловленные особенностями нелинейной динамики биологических молекул. Изменение механических реакций клеток и тканей потенциально отражает степень «повреждения» биологической системы и может быть использовано в качестве нового диагностического инструмента для дополнения традиционных биохимических и молекулярно-генетических методов, используемых в настоящее время в клинической практике.

Перспектива применения результатов механобиологии для классификации заболеваний, связанных с механическими изменениями клеток и тканей, предполагает изучение четко определенных и стандартизированных методов и протоколов сбора и обработки данных. Прямое исследование механобиологических реакций клеток с помощью когерентной фазовой микроскопии с последующим определением «значимых» коллективных степеней свободы позволяет определить динамическую устойчивость биологических систем, в том числе тканей, и их качественное изменение с накоплением «повреждений».

Современные исследования клеточной биологии установили силовые и физические факторы, наряду с биохимическими, в качестве основных механизмов, определяющих клеточную динамику. При этом активная реакция клеток на внешние факторы, а также адаптация клетки к окружающей среде и ее механические свойства стимулируют метастатический (эпигенетический) потенциал.

\section{Нелинейная динамика ДНК и коллективные моды экспрессии}

Важной областью механобиологии является нелинейная динамика ДНК, определяющая основные закономерности экспрессии, формирование фенотипа и динамики клеток, при подчинении последних конечно-амплитудным возмущениям. 
Возмущения представляют собой коллективные моды (так называемые открытые комплексы), ответственные за механизмы экспрессии, конформационные переходы в ДНК, включая процессы репликации, транскрипции и деления клеток [1, 2].

Нелинейные динамические процессы в ДНК развиваются на масштабах времени от фемтосекунд до секунд и от амплитуд малых колебаний отдельных атомов или атомных групп до движений с большой амплитудой фрагментов полинуклеотидных цепей, связанных с локальным раскручиванием и раскрытием двойной спирали с образованием дефектов - «открытых комплексов» (рис. 1).

Нелинейная модель динамики ДНК предложена в [3], получила развитие в статье [2], и позволила связать трансформацию конечно-амплитудных мод дефектов («открытых комплексов») различной динамической природы (breathers, solitary modes and blow-up dissipative structures) связать с новым классом критических явлений в конденсированных средах с дефектами - структурно-скейлинговыми переходами [4]. Принципиальное значение для описания многомасштабной динамики биологических систем (от трансформации ДНК до деления клеток) имеет определение параметра порядка - параметра структурного скейлинга, играющего роль «эффективной температуры» неравновесной системы с дефектами [5] и определяющего «механобиологический» эпигенетический ландшафт биологической системы [6].

Эпигенетический ландшафт может быть интерпретирован как неравновесная свободная энергия ансамбля биологических молекул, определяемая взаимодействием множества структурных составляющих, соответствующих конкретному генотипу. Количество актов взаимодейст- вия для простых организмов оценивается как $10^{7200}[7,8]$, что не позволяет реконструкцию свободной энергии для данного набора переменных. Однако введение коллективных переменных, характеризующих открытые комплексы, с динамикой, определяемой видом неравновесной свободной энергии, представляется естественным для описания стадийности эволюции ДНК и цитоскелетных структур.

Последовательность трансформации типов коллективных мод при структурноскейлинговых переходах позволила предложить описание дальнодействующих механизмов в ДНК, включая формирование фенотипов как спектра конечно-амплитудных мод бризерного типа, с последующей трансформацией последних в автосолитонные моды и диссипативные структуры обострения, обеспечивающие механизмы транскрипции, формирование хромосомных структур для реализации естественного сценария деления клеток [9].

Важность изучения динамики открытых состояний (открытых комплексов) в ДНК обусловлена также экспериментальными наблюдениями in vivo, связывающими многомасштабную динамику открытых состояний с резким уменьшением жесткости и повышением пластичности ДНК. Термодинамические аспекты открытых состояний в ДНК можно рассматривать как ключевую проблему для понимания функционирования ДНК. Статистический подход к описанию коллективного поведения открытых комплексов в ДНК позволил предложить статистическую термодинамику и уравнение динамики ДНК в обобщенной форме Гинзбурга-Ландау и показать, что многомасштабная динамика дефектов отражает специфический тип критичности (структурно-скейлинговые переходы), определяющий стадийность трансформа-

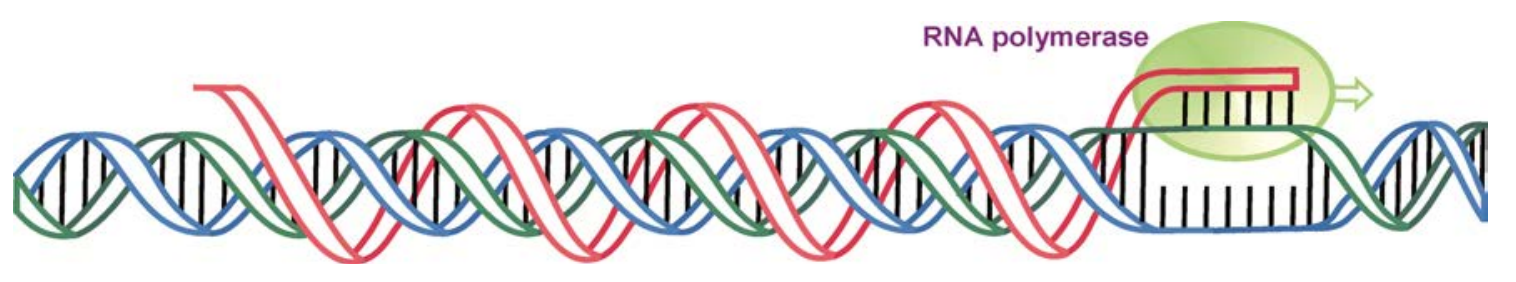

Рис. 1 Структура ДНК и образование открытых комплексов 
ционных процессов, механобиологию «пластичности» и деления субклеточных и клеточных структур (см рис. 1).

Структурные переходы, индуцированные открытыми состояниями в ДНК, можно рассматривать как следствие эволюции мод дисторсии вследствие развития дефектов при воздействии деформации или тепловых возмущений. Роль дефектов важна также при формировании одиночной полинуклеотидной цепи, если последняя рассматривается как непериодический одноосный кристалл, состояния равновесия которого достигаются при формировании дисторсии, включающей моды «открытых комплексов» и моды, определяющие вращение между парами оснований. При этом моды вращения связаны геометрически с модами открытых состояний и введены в [2] как локализация группы симметрии тензора дисторсии. Микроскопический параметр, связанный с открытыми комплексами, характеризует локальную деформацию на малом сегменте $2 \mathrm{~d}$ (около 15-20 пар оснований) с нормальным смещением $\vec{B}=B \vec{v}$ в области сегмента $\vec{S}_{d}=S_{d} \vec{v}\left(S_{d} \sim \pi d^{2}\right)$ с ориентацией $\vec{v}$,

$$
S_{i k}=S v_{i} v_{k} \text {, }
$$

где $S=S_{d} B$. Мода вращения представляет антисимметричную часть локализованной дисторсии при локализованном сдвиге в области сегмента $\vec{S}_{d}=S_{d} \vec{l}$

$$
S_{i k}=1 / 2 S\left(v_{i} l_{k}-l_{i} v_{k}\right) \text {. }
$$

Статистическое описание позволило предложить феноменологию локализованных мод дисторсии, основанную на представлении неравновесной свободной энергии. Среднее значение открытого комплекса $\quad p_{i k}=\left\langle s_{i k}\right\rangle$ для одноосного случая $\left(p \sim p_{i k}\right)$ соответствует минимуму неравновесной свободной энергии в форме Гинзбурга-Ландау

$$
\begin{aligned}
& F=\frac{1}{2} A\left[1-\left(\frac{\delta}{\delta_{*}}\right)\right] p^{2}-\frac{1}{4} B p^{4}+ \\
& +\frac{1}{6} C\left[1-\left(\frac{\delta}{\delta_{c}}\right)^{4}\right] p^{6}-D \sigma p+\chi\left(\nabla_{l} p\right)^{2},
\end{aligned}
$$

Где $\sigma$-компонента тензора напряжений. Вторая структурная переменная - параметр структурного скейлинга $\delta$, представляет собой отношение двух характерных масштабов: длины $2 d$ сегмента, соответствующего открытому комплексу, и расстояния между открытыми комплексами. Точки бифуркации $\delta_{*}=1,3, \delta_{c}=1$ разделяют качественно различные области метастабильности свободной энергии и играют роль, аналогичную характерным температурам в теории Гинзбурга-Ландау. Градиентный член в (4) описывает нелокальное взаимодействие в поле дисторсий; $A, B, C, D$ и $\chi$ являются феноменологическими параметрами. Кинетика открытых комплекса задается уравнениями эволюции для указанных структурных переменных:

$$
\begin{gathered}
\frac{d p}{d t}=-\Gamma_{p} \frac{\partial F}{\partial p}, \\
\frac{d \delta}{d t}=-\Gamma_{\delta} \frac{\partial F}{\partial \delta},
\end{gathered}
$$

где $\Gamma_{p}$ и $\Gamma_{\delta}-$ кинетические коэффициенты. Переход через точку бифуркации $\delta_{*}$ приводит к проникновению в область метастабильности и генерации коллективных конечно-амплитудных мод дисторсии: динамического бризера $\left(\delta \rightarrow \delta_{*}\right)$ и автосолитонной (уединенной) волны $\left(\delta_{c}>\delta>\delta_{*}\right)$, рис. 2. Динамика уединенной волны и ее параметры (амплитуда $\mathrm{p}_{a}$, скорость $V$ и ширина фронта волны $L_{B}$ ) дается автомодельным решением [4]:

$$
\begin{aligned}
& p=\frac{1}{2} p_{a}\left[1-\operatorname{tahn}\left(\zeta L_{B}^{-1}\right)\right], \\
& L_{B}=\frac{4}{p_{a}}\left(2 \frac{\chi}{A}\right)^{1 / 2}, \\
& V=\chi A\left(p_{a}-p_{m}\right) / 2 \zeta^{2}
\end{aligned}
$$



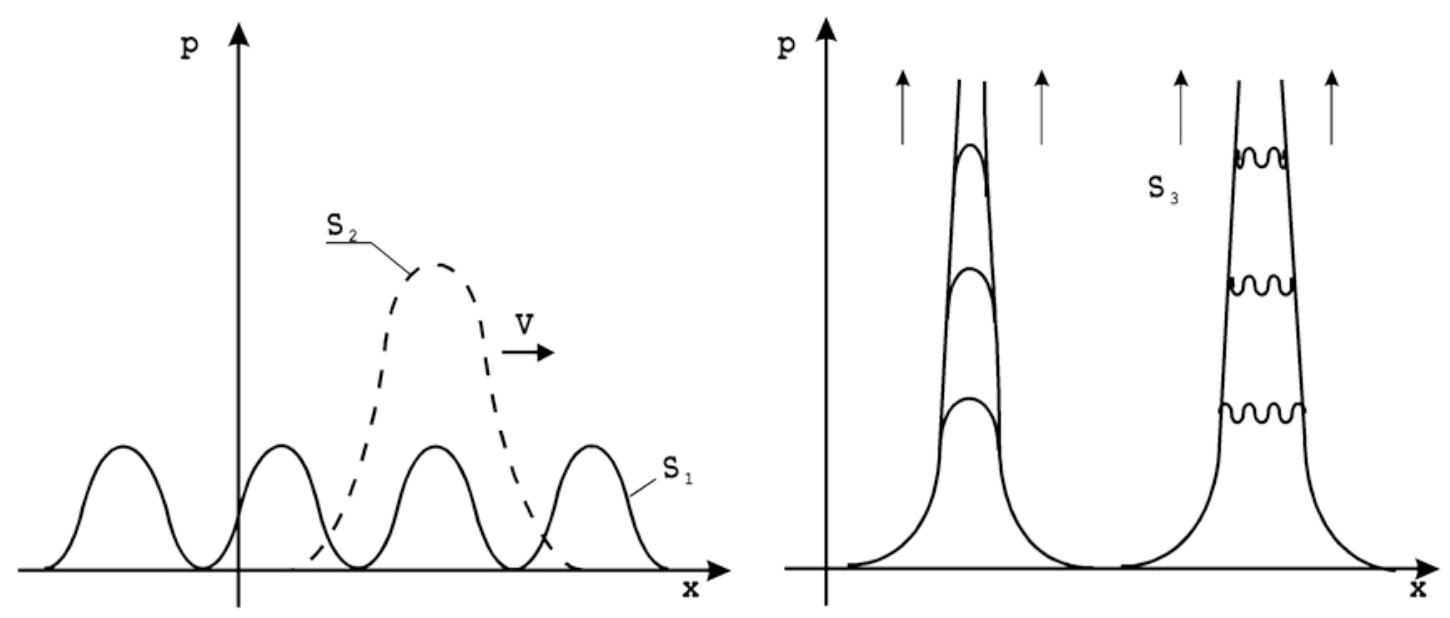

Рис. 2. Коллективные моды «открытых комплексов»: бризеры $S_{1}$, автосолитонные моды $S_{2}$, диссипативные структуры обострения $S_{3}$

где $\left(p_{a}-p_{m}\right)-$ скачок $p$ в области метастабильности

Переход через точку бифуркации $\delta_{c}=1$ приводит к изменению бистабильного потенциала на потенциал с бесконечной глубиной второго минимума и качественными изменениями динамики открытых комплексов - формированием многомасштабных «обостряющихся» мод (см. рис. 2), определяемых автомодельным решением вида

$$
\begin{aligned}
& p(x, t)=\varphi(t) f(\zeta), \\
& \zeta=\frac{x}{L_{c}}, \\
& \varphi(t)=\Phi_{0}\left(1-\frac{t}{t_{c}}\right)^{-m},
\end{aligned}
$$

где $m>0, \quad \Phi_{0}>0$ - параметры, определяющие нелинейность свободной энергии, при $L_{c}$ и $t_{c}$ - пространственные и временные масштабы, соответствующие кинетике режимов с «обострением». Последовательность реализации коллективных мод (бризеров, автосолитонных и диссипативных структур обострения) при согласованной кинетике параметра структурного скейлинга $\delta$ на заданном эпигенетическом ландшафте (3) обеспечивает естественный трансформационный цикл в биологической системе, включающий формирование фенотипа, включение механизмов транскрипции в условиях последователь- ной «укладки» ДНК и формирования хромосомных структур при их последующем разделении «обостряющейся» модой как механизм деления клеток [9] (рис. 3).

Автомодельные решения, соответствующие коллективным модам дефектов (бризеры, автосолитонные моды и диссипативные структуры обострения) характеризуют «притягивающие множества» решений (аттракторов), которые определяют качественно различную динамику биологической системы на соответствующем эпигенетическом ландшафте в зависимости от «восприимчивости» системы, определяемой значениями и кинетикой параметра структурного скейлинга $\delta$. Множество бризерных мод, формирующихся в окрестности критической точки $\delta \approx \delta_{*}$, представляют собой коллективные степени свободы, определяющие фенотип клетки для конкретного генотипа и эпигенетического ландшафта. Распределение бризерных мод в ансамбле ДНК формирует новые пространственно-временные масштабы, изменяет текущую восприимчивость системы (в терминах параметра структурного скейлинга $\delta$ ), что приводит к формированию автосолитонных мод, динамика которых обеспечивает процесс транскрипции, сопровождающийся резким увеличением кривизны ДНК, формированием ансамбля гистонов при одновременной плотной «укладке» молекул ДНК. 


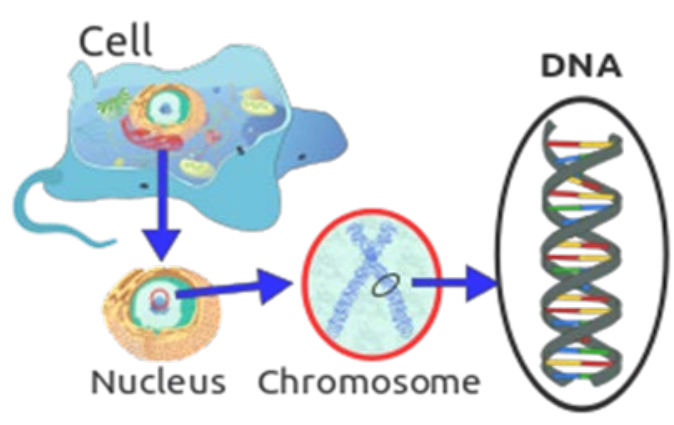

$a$

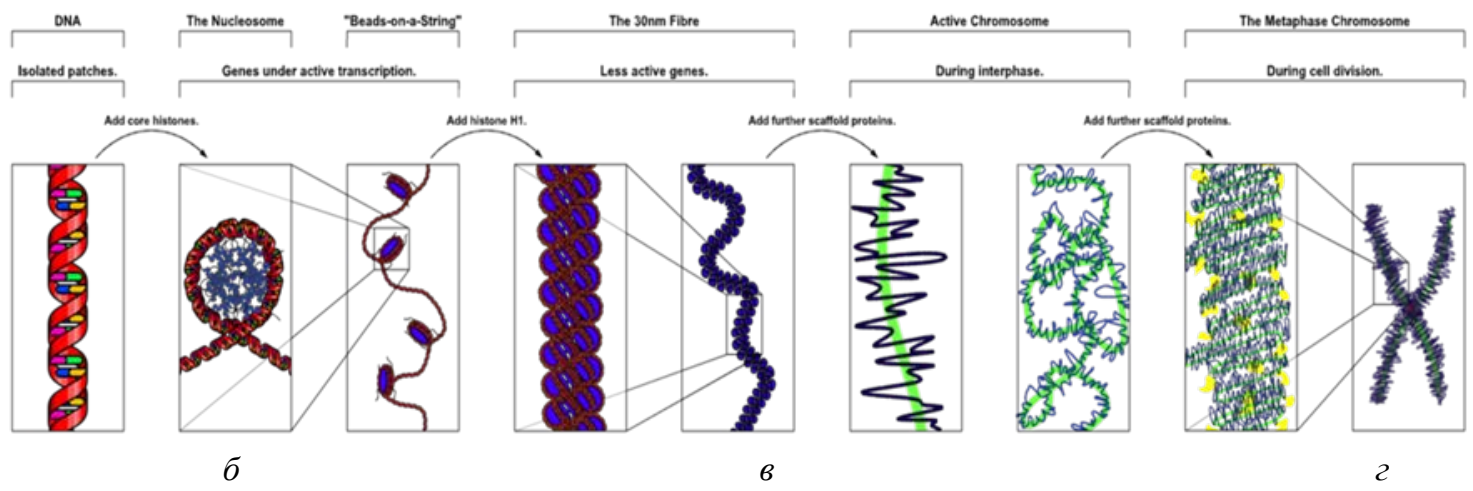

Рис. 3. Структура клетки и трансформации ДНК:

а-структура клетки, б-топология гистона, в-укладка гистонов, г-деление клетки

Формирование гистонов происходит в условиях роста амплитуды автосолитонной моды, сопровождается резким изменением и ростом кривизны ДНК $\chi=(\partial p / \partial s)_{f} \quad(S$-продольная ось двойной спирали), достигающей максимального значения при $\delta \rightarrow \delta_{c}$ в центромере области «встречи» участков ДНК различной кривизной. Эта область может рассматриваться в качестве лабильной «сшивки», аналогичной зарождению «сидячей» дислокации с низкой подвижностью (высокой энергией активации) [9]. «Исчерпание пластичности» в цитоскелетной организации из плотноупакованных областей-гистонов приводит к подчинению последних динамике «обостряющихся мод», неограниченному росту открытых комплексов, разрыву двойной спирали и формированию хромосомных структур (см. рис. 3).

Закономерности критичности как ранние признаки развития рака (на примере клеток MCF-7 рака молочной железы) исследованы в $[7,8]$ и установлены отличительные признаки экспрессии, соответст- вующие областям с выраженной, переходной и устойчивой динамикой. Автомодельные признаки, соответствующие моно- и бимодальным переходам в динамике экспрессии, идентифицируются как когерентная динамика экспрессии, аналогичная сценариям фазовых переходов в феноменологии Гинзбурга-Ландау.

\section{Лазерная микроскопия прижизненной динамики и морфологии раковых и нормальных клеток}

Дифференциация нормальных и патологически измененных клеток методом лазерной микроскопии осуществлялась на основе измерения фазовой толщины клеток, вычислением морфометрических показателей и обоснованием критериев дифференциации. Для получения критерия дифференциации нормальных и раковых клеток применялся статистический анализ на основе непараметрического теста ранговой корреляции Спирмена, а также двухвыборочного непараметрического критерия Уилкоксона-Манна-Уитни. 
Культуры клеток. Методики дифференциации разработаны для культур раковых и нормальных эпителиальных клеток, выделенных из аналогичного источника (ткани, органа). В качестве модельной линии клеток злокачественной опухоли эпителиального происхождения (раковых) была выбрана линия MCF-7 (карцинома молочной железы человека), в качестве нормальных клеток - MCF-10А (эпителий молочной железы человека). В сравнительных исследованиях использовали также нормальные клетки линии НЕК 293 (эмбриональные клетки почки человека). Линии МСF-7 и НЕК 293 культивировали в среде DMEM с добавлением 2 мM $\mathrm{L}$-глутамина и 10\%-ной фетальной бычьей сыворотки. Клетки MCF-10А выращивали в среде DMEM/F12 с добавлением 2 мМ L-глутамина, 5\%-ной лошадиной сыворотки, эпителиального фактора роста, EGF (20 нг/мл), гидрокортизона (0,5 нг/мл) и инсулина (10 нг/мл). Клетки культивировали в условиях $5 \% \mathrm{CO}_{2}$, при $37^{\circ} \mathrm{C}$.

Подготовка образцов. Подготовку препарата клеток человека осуществляли помещением в чашку Петри покровных стекол и стерилизации в сухожаровом шкафу. В стерильную чашку Петри со стеклами в условиях ламинарного бокса вносили 10 мл культуральной среды и 1 мл клеточной суспензии с концентрацией $1 \times 10^{5}$ клеток/мл. Чашку Петри помещали на 48 часов в $\mathrm{CO}_{2}$-инкубатор, в условия 5\%-ного содержания углекислого газа, при $\mathrm{T}=37^{\circ} \mathrm{C}$. По истечении указанного времени готовили препарат для сканирования методом лазерной микроскопии.

Измерения оптической толщины клеток методом лазерной интерференционной микроскопии. Измерения оптической толщины и флуктуаций оптической толщины клеток выполняли на базе Пермского федерального исследовательского центра УрО РАН (г. Пермь) с использованием лазерного интерференционного микроскопа МИМ-340. Всего было измерено 93 клетки культуры MCF-7, 96 клеток культуры НЕК 293 и 100 клеток культуры MCF-10А. Результаты типовых измерений представлены на рис. 4, где четко визуализируются область адгезии живых клеток (зеленый цвет), тонкий слой цитоплазмы (желтый цвет), ядра (красный цвет) и ядрышки (темно-красный цвет). К главным преимуществам лазерного микроскопа МИМ-340 рис. 5

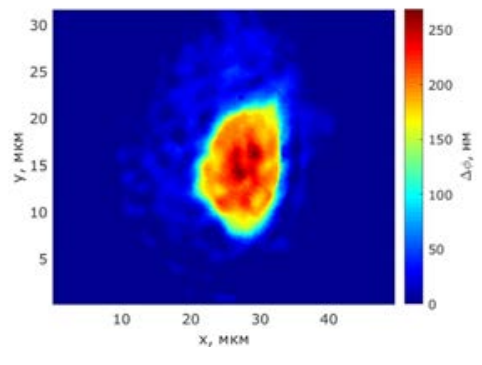

$a$

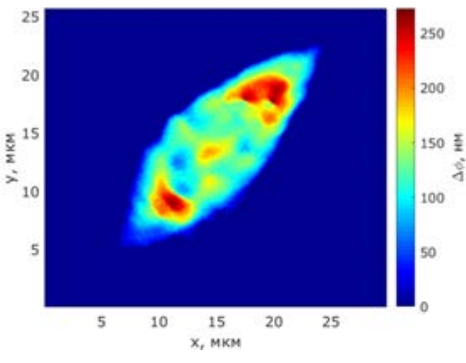

$\sigma$

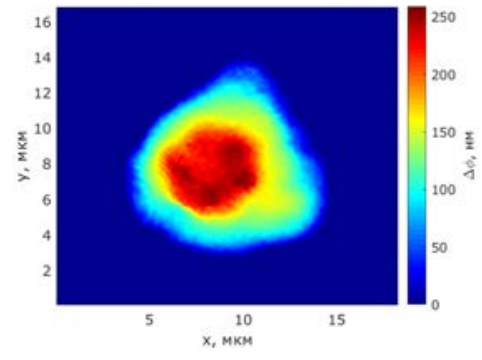

B

Рис. 4. Фазовые изображения клеток культур: $а$ - MCF-7, б - НЕК 293, в- MCF-10А

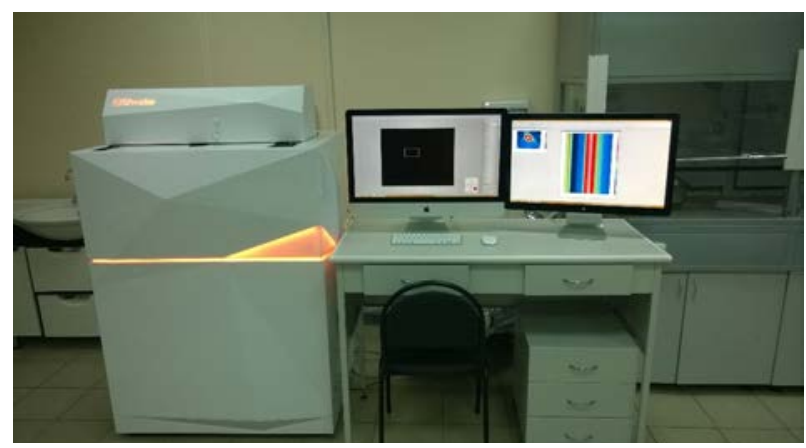

Рис. 5. Внешний вид лазерного микроскопа МИМ-340 
относятся: высокое разрешение в латеральной плоскости (10-100 нм) и по вертикали (0,3 нм), частота записи фазовых изображений (33 Гц) и наличие предметного стола, позволяющего позиционировать исследуемый объект с нанометровой точностью (точность позиционирования - 150 нм).

Принципиальная оптическая схема лазерного модуляционного интерференционного микроскопа изображена на рис. 6. Измерение локальных задержек фазы осуществляется следующим образом. Когерентное излучение, генерируемое лазером красного цвета 1 (длина волны 655 нм), проходит через светоделитель 3 и разделяется на два луча. Первый «предметный» луч фокусируется микрообъективом «предметного плеча» 7 на исследуемом объекте 8. Второй луч фокусируется микрообъективом опорного плеча 9 на зеркальной поверхности фазового модулятора 10. После отражения оба луча, пройдя через светоделитель 3 , тубусные линзы 4 и проектив 6, отражаются от поворотного зеркала 5 и попадают в камеру измерительного канала 12, где возникает и фиксируется интерференционная картина. Также в описанной оптической схеме

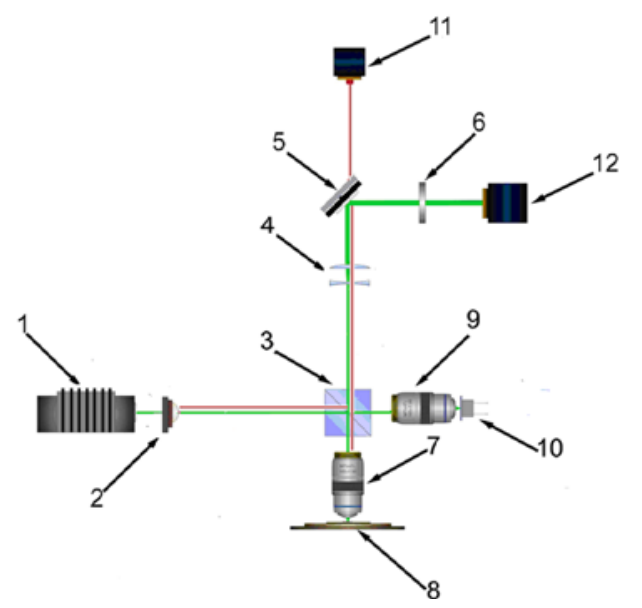

Рис. 6. Принципиальная оптическая схема лазерного микроскопа МИМ-340, где 1 - лазер, 2 - светодиод (бельй свет), 3 - светоделитель, 4- тубусная линза, 5 - поворотное зеркало, 6 - проектив, 7 -микрообъектив предметного плеча,

8 - исследуемый объект, 9-микрообъектив опорного плеча, 10 - фазовый модулятор,

11 - циифровая камера навигачиооного канала, 12 - циифровая камера измерительного канала есть камера навигационного канала 11, которая необходима при позиционировании исследуемого объекта 8.

Для получения величин локальных задержек фазы используется модернизированный трехшаговый метод [11]. Благодаря фазовому модулятору при каждом измерении фиксируются четыре интерферограммы, которые могут быть представлены следующей системой уравнений:

$\left\{\begin{array}{l}I_{0}(x, y)=A(x, y)+B(x, y) \cos (\Delta \phi(x, y)) \\ I_{1}(x, y)=A(x, y)+B(x, y) \cos (\Delta \phi(x, y+k d)) \\ I_{2}(x, y)=A(x, y)+B(x, y) \cos (\Delta \phi(x, y+2 k d)) \\ I_{3}(x, y, t)=A(x, y)+B(x, y) \cos (\Delta \phi(x, y+3 k d(t)))\end{array}\right.$

Разность фаз $\Delta \phi(x, y)$ вычисляется как $\Delta \phi(x, y)=$

$=\operatorname{arctg}\left[\frac{\sqrt{\left[\left(I_{1}-I_{2}\right)+\left(I_{0}-I_{3}\left(t_{0}\right)\right)\right]} \cdot\left[3\left(I_{1}-I_{2}\right)-\left(I_{0}-I_{3}\left(t_{0}\right)\right)\right]}{I_{1}+I_{2}-I_{0}-I_{3}\left(t_{0}\right)}\right]$ (8)

Функция $\Delta \phi$ несет в себе количественную информацию об оптических и геометрических свойствах измеряемого объекта и определяется следующим соотношением

$$
\Delta \phi(x, y, t)=\frac{1}{2 \lambda} \int\left[n(x, y, z, t)-n_{0}\right] d z,
$$

где $n(x, y, z, t)$ - показатель преломления объекта, $n_{0}$ - показатель преломления среды, $\lambda$ - длина волны излучения, $z$ - высота объекта в заданной точке.

Исследование прижизненной динамики клеток методом лазерной интерферометрии. Методом когерентной фазовой микроскопии реализованы три режима записи данных на 300 здоровых и раковых клетках (рис. 7): фазовое изображение клетки (рис. 7, $a$ ), трек-диаграмма (изображение в виде изоуровней, рис. 7,6 ), трек-диаграмма (изображение в виде поверхности, рис. 7,6 ).

В процессе исследований была отработана методика измерения динамических процессов в живых клетках посредством анализа их фазовых изображений (рис. 8, 9). 


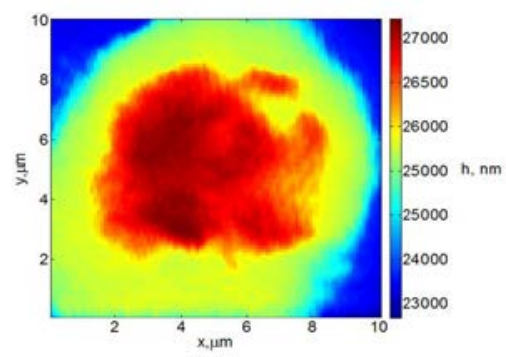

$a$
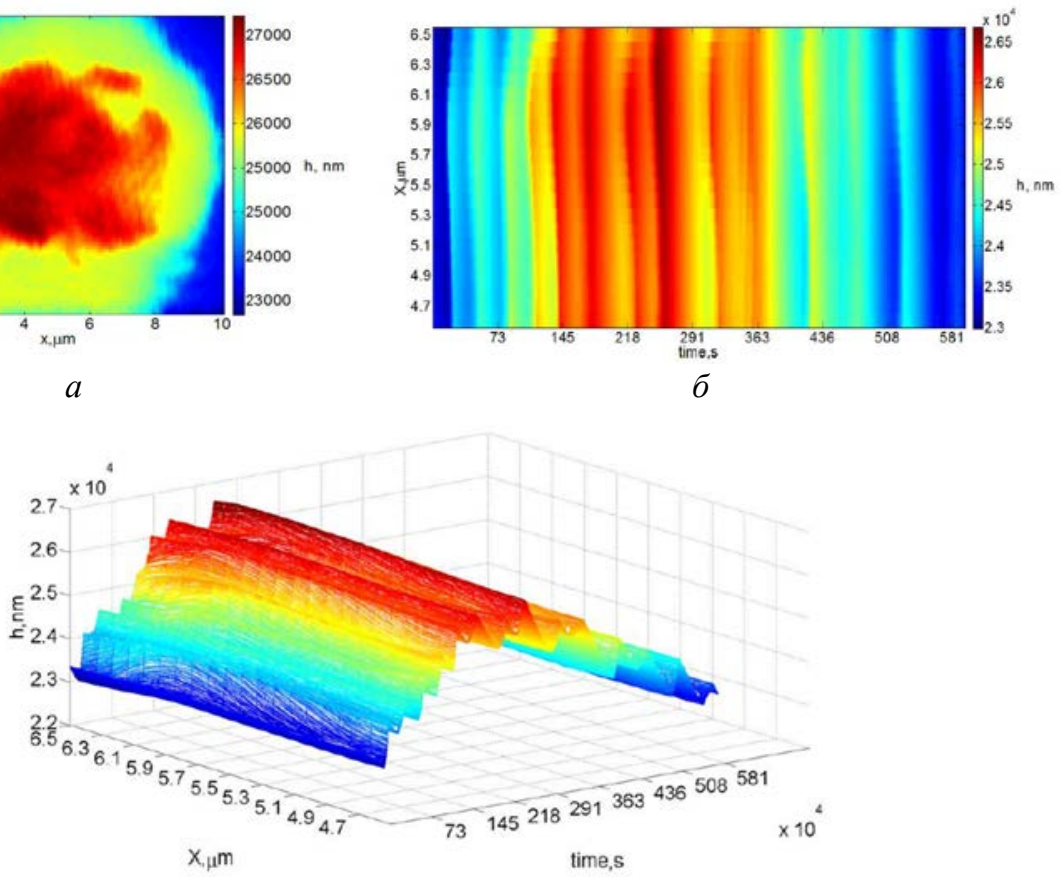

B

Рис. 7. Режимы записи данных лазерной микроскопии

Mc
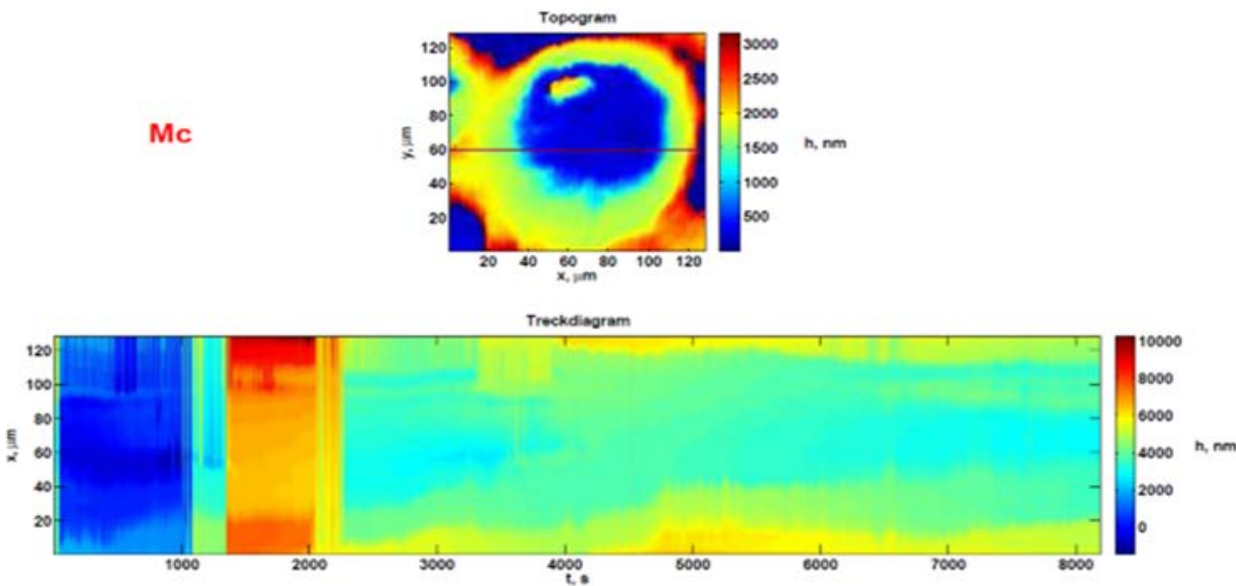

Рис. 8. Топограмма (а) и трек-диаграмма (б) препарата раковой клетки культуры НСТ116

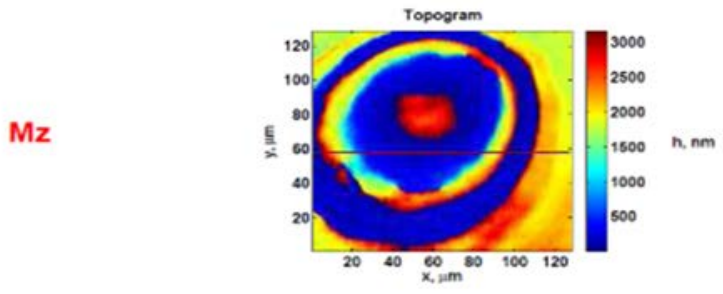

Treckdiagram

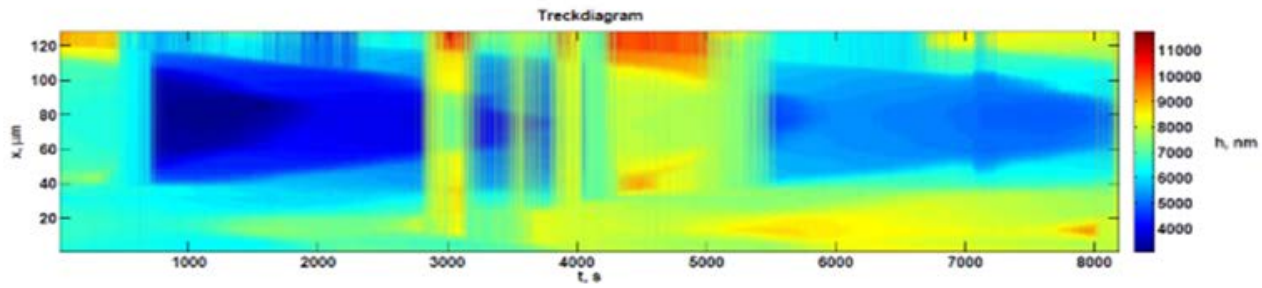

Рис. 9. Топограмма (а) и трек-диаграмма (б) препарата здоровой клетки ТТК 
Исследования позволили идентифицировать наиболее оптически плотные области как ядра и ядрышки клеток, по которым в дальнейшем производилось измерение прижизненной динамики (рис. 10).

Для анализа использован метод обработки данных динамической когерентной фазовой микроскопии клеток - метод максимумов модулей вейвлет-преобразования (WTMM 1D), который позволил получить искомый спектр сингулярностей мультифрактала. Установлены признаки мультифрактальности для клеток «в норме» и монофрактальная динамика флуктуаций фазовых толщин для раковых клеток [10].
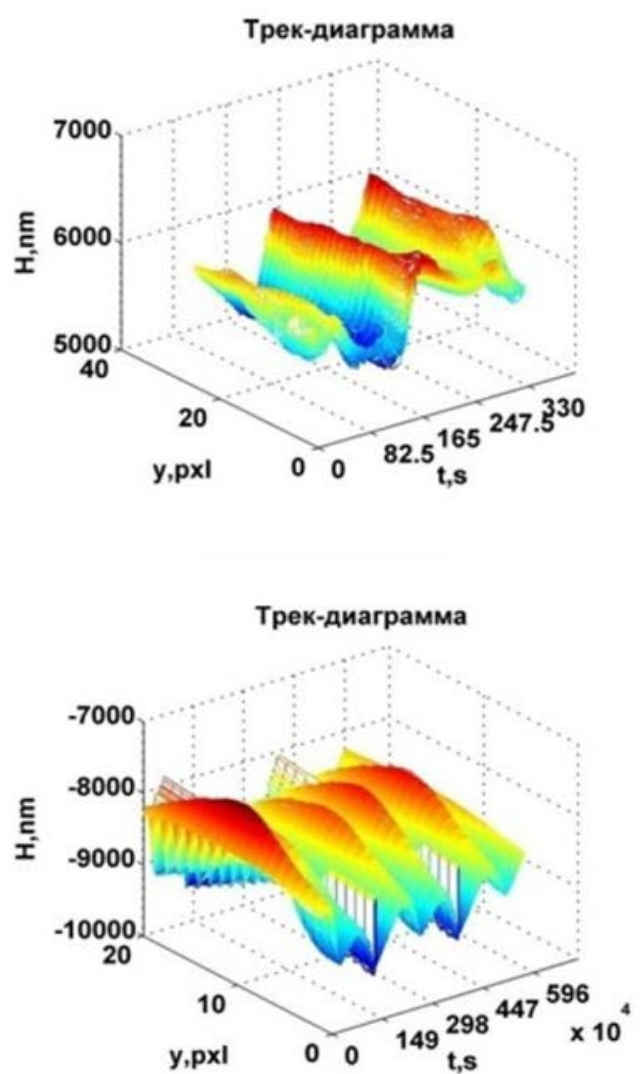

Рис. 10. Трек-диаграмма флуктуачий фазовой толщины раковой клетки (НСТ116)

и здоровой клетки ТТК в норме вдоль скан-линии протяженностью 2 мкм и временем регистращии 330 и 596 c, соответственно

Морфометрические показатели фазовых изображсений клеток. В качестве количественных характеристик, на которых базируется критерий дифференциации патологически измененных и нормальных эпителиальных клеток, использовались морфометрические показатели клеток. Под морфометрическими показателями понимаются геометрические характеристики фазовых изображений клеток, а именно: высота, минимальный и максимальный диаметры, периметр, площадь и объем. Данные характеристики применительно к исследованиям биологических объектов на основе методов количественной фазовой микроскопии были впервые подробно описаны в работе [12], посвященной исследованию нормальных и патологически измененных эритроцитов человека. Авторами было показано, что такие морфометрические показатели, как периметр и объем фазовых изображений, могут быть использованы в качестве маркеров патологии [13]. Для вычисления морфометрических показателей клеток определялся контур фазового изображения по методу Кэнни [14]. На рис. 11 представлено фазовое изображение клетки MCF-7 с выделенным по методу Кэнни контуром.

Высота фазового изображения рассчитывалась как разница между минимальным и максимальным значениями локальных задержек фазы внутри контура:

$$
h=\Delta \phi_{\max }-\Delta \phi_{\min },
$$

где $h$ - высота фазового изображения клетки, $\Delta \phi_{\max }, \Delta \phi_{\min }$ - максимальное и минимальное значения оптической толщины клетки соответственно. Далее в рамках

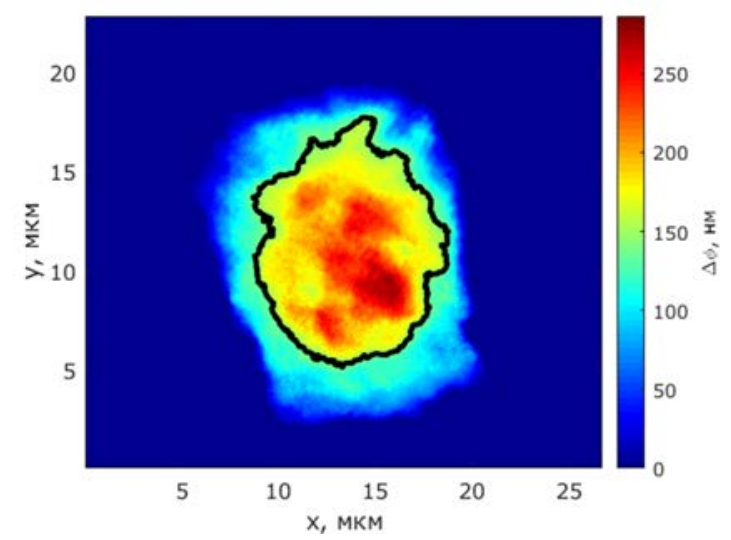

Рис. 11. Фазовое изображение раковой клетки MCF-7

Сплошная линия выделяет контур клетки 
данного контура рассчитывались все возможные диаметры и из них выбирался минимальный и максимальный $\left(d_{\min ,}, d_{\max }\right)$. Периметр, площадь и объем фазового изображения клетки рассчитывались согласно следующим соотношениям:

$$
\begin{gathered}
P=l n_{\Omega}, \\
S=l^{2}\left(n_{\Omega}+n_{\omega}\right), \\
V=\sum_{x \in \omega_{x}, \Omega_{x}} \sum_{y \in \omega_{y}, \Omega_{y}} l^{2} \Delta \phi(x, y),
\end{gathered}
$$

где $P$ - периметр фазового изображения клетки, $l$ - размер пикселя, $n_{\Omega}-$ количество точек, принадлежащих множеству точек контура $\Omega, n_{\omega}-$ количество точек внутри контура $\Omega, V$ - объем фазового изображения клетки, $\Delta \phi(x, y)-$ значение фазовой толщины клетки в точке $(x, y)$.

Сравнительный анализ морфометрических показателей раковых и нормальных клеток. Анализ морфометрических параметров для дифференциации раковых и нормальных клеток проводился для двух случаев: сравнения клеток культуры MCF-7 с клетками линии НЕК 293 и сравнения клеток культуры MCF-7 с клетками MCF-10A. В качестве метода оценки статистически значимой разницы был выбран двухвыборочный непараметрический тест Уилкоксона-Манна-Уитни. Для оценки взаимосвязи между исследуемыми показателями одной культуры применяли непараметрический тест ранговой корреляции Спирмена.

На первом этапе было проведено сравнение морфометрических показателей клеток злокачественной опухоли эпителиального происхождения из молочной железы человека MCF-7 и нормальных клеток почки человека HЕK 293. Уста- новлено (рис. 12), что по всем морфометрическим показателям исследуемые выборки имеют статистически значимые различия $(p<0,001)$.

Проведена оценка парной корреляции морфометрических показателей культур MCF-7 и НЕК 293. В таблице представлены результаты оценки парных корреляций высоты фазового изображения клетки $h$, объема фазового изображения клетки $V$ и среднего радиуса фазового изображения клетки $M(r)$ определяемого как

$$
M(r)=\frac{\left(d_{\max }+d_{\min }\right)}{4} .
$$

Данные показатели выбраны на основе анализа распределений их относительной вероятности (рис. 13). Критерием служила малость области пересечения распределений относительной вероятности исследуемых параметров. Полученные результаты показали положительные корреляционные зависимости взаимосвязи для всех пар за исключением $h-M(r)$ для культуры НЕК 293.

На основе результатов статистического и корреляционного анализа для сравнения морфометрических свойств клеток культур МСF-7 и НЕК 293 предложено использовать безразмерные комплексы $h / M(r)$ и $V /\left(0,5 \lambda S_{0}\right)$, где $S_{0}=4 / 3 \pi r^{2}$. На рис. 14 представлены гистограммы относительной вероятности этих комплексов. Видно, что они накладываются одна на другую и не позволяют дифференцировать клетки из разных источников (тканей, органов): клетки злокачественной опухоли молочной железы эпителиального происхождения MCF-7 и нормальные клетки эпителия почки HEK 293.

Корреляционные взаимосвязи высоты фазового изображения клетки $h$, объема фазового изображения клетки $V$ и среднего радиуса фазового изображения клетки $M(r)$ для культур MCF-7, HEK 293 и MCF-10A

\begin{tabular}{|c|c|c|c|}
\hline \multirow{2}{*}{ Культура клеток } & \multicolumn{3}{|c|}{ Корреляционные взаимосвязи } \\
\cline { 2 - 4 } & $h-V$ & $h-M(r)$ & $V-M(r)$ \\
\hline MCF-7 & $0,6097^{\star \star \star}$ & $0,3292^{\star \star \star}$ & $0,8739^{\star \star \star}$ \\
\hline HEK 293 & $0,4739^{\star \star \star}$ & $-0,0175$ & $0,8021^{\star \star \star}$ \\
\hline MCF-10A & $0,4205^{\star \star \star}$ & $-0,0110$ & $0,8388^{\star \star \star}$ \\
\hline
\end{tabular}




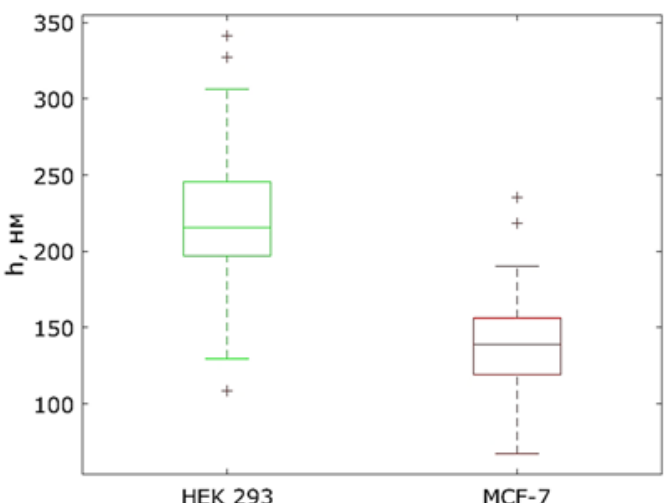

$a$
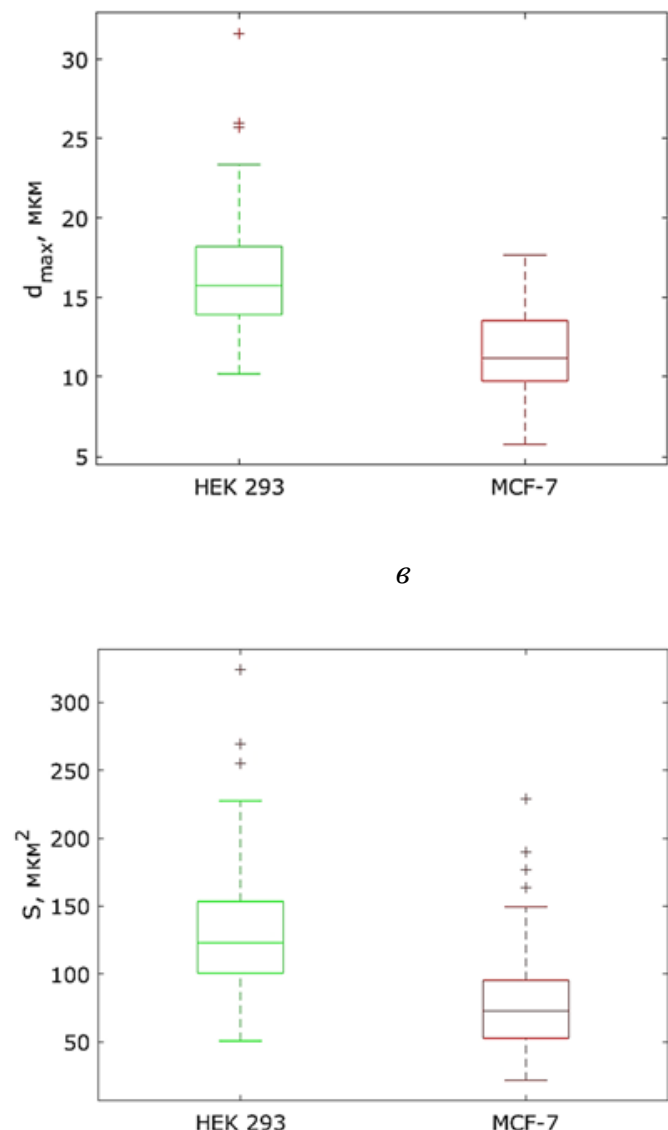

$\partial$

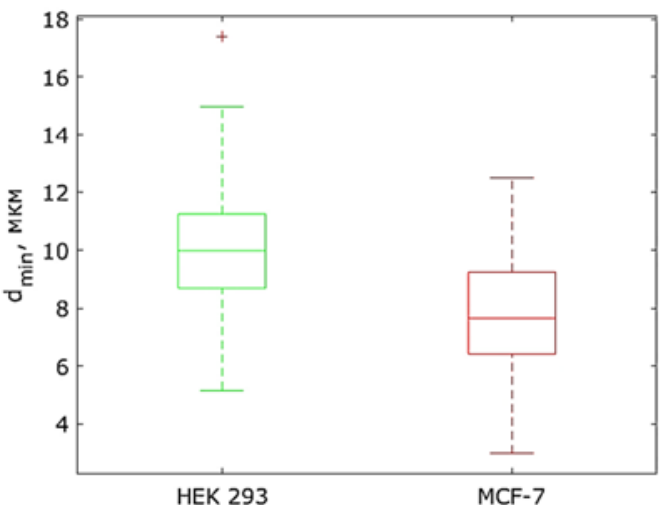

6

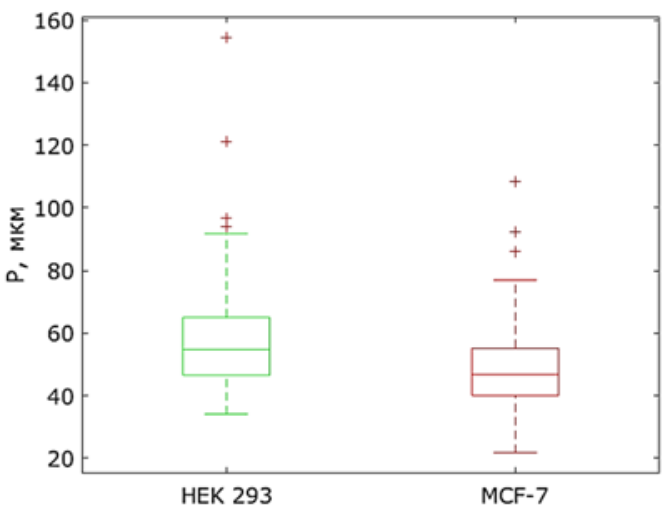

2

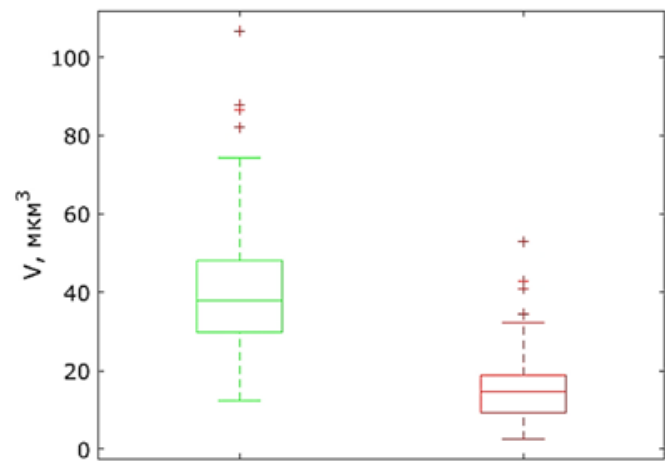

HEK 293
MCF-7

Рис. 12. Сравнения морфометрических показателей нераковых (HEK 293) и раковых (MCF-7) клеток: сравнение высоты фазового рельефа (а); по минимальному и максимальному диаметрам фазового изображения (б, в); по периметру и площади фазового изображения (2, д); объема фазового рельефа клеток (е). Средняя горизонтальная линия - это медианное значение выборки. Верхняя и нижняя горизонтальные граниџы бокса-75\%-ная и 25\%-ная квантили соответственно. Верхний и нижний доверительные интервалы соответствуют экстремальным значениям выборки. Красные точки (+) - точки выборки, которые выходят за границы доверительных интервалов 

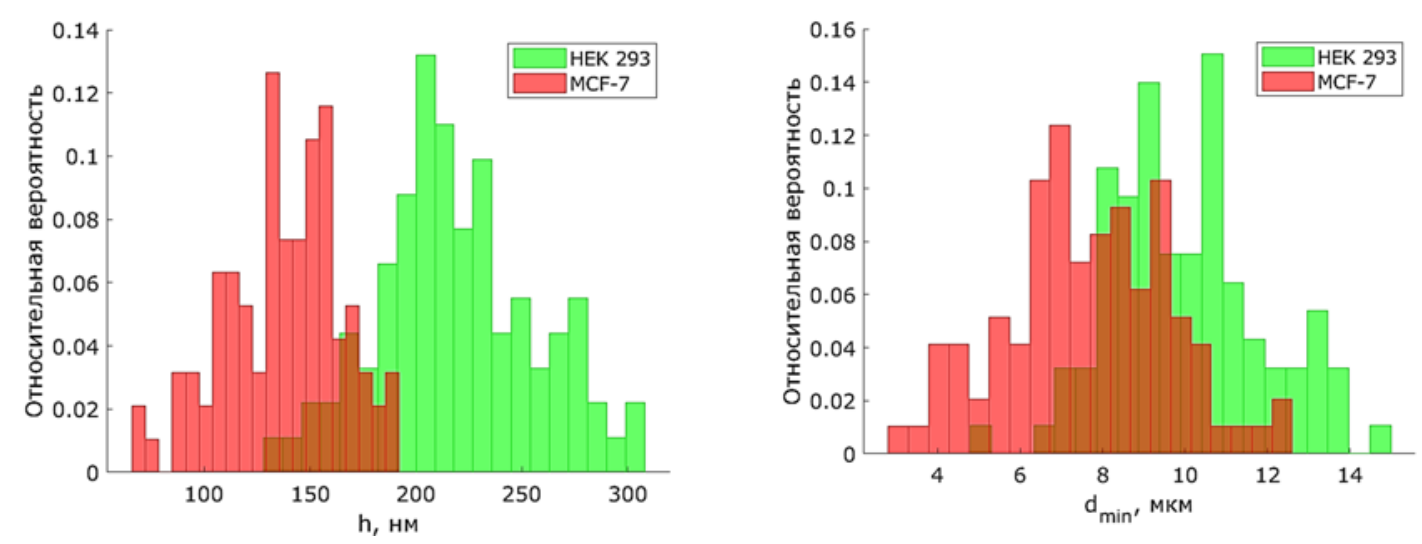

$a$
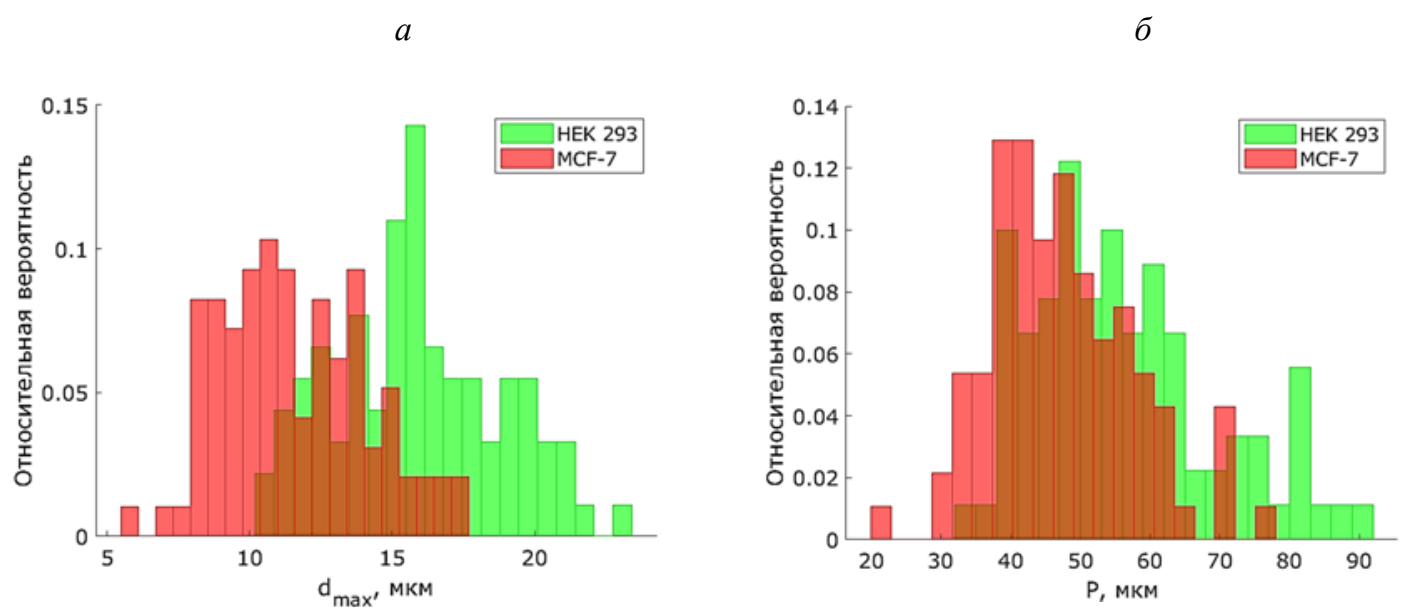

6
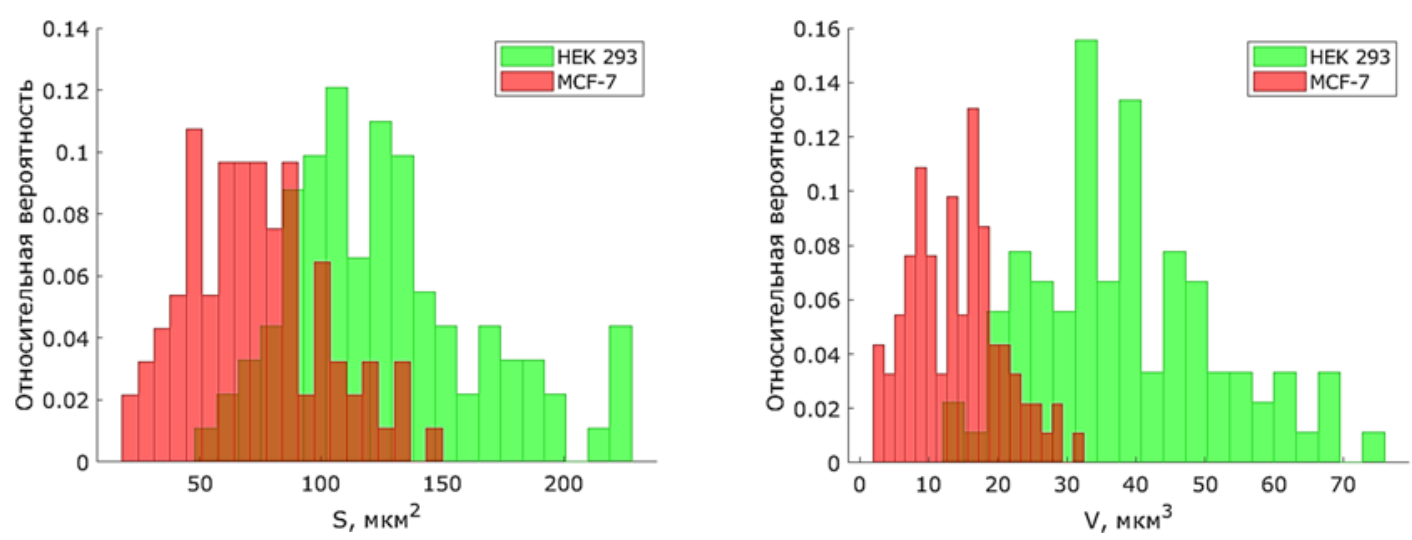

$\partial$

$e$

Рис. 13. Распределения высоты (а), минимального диаметра (б), максимального диаметра (в), периметра (2), площади (д) и объема (е) фазовых изображений клеток культур МСF-7 (красный ивет) и НЕК 293 (зеленый ивет) 


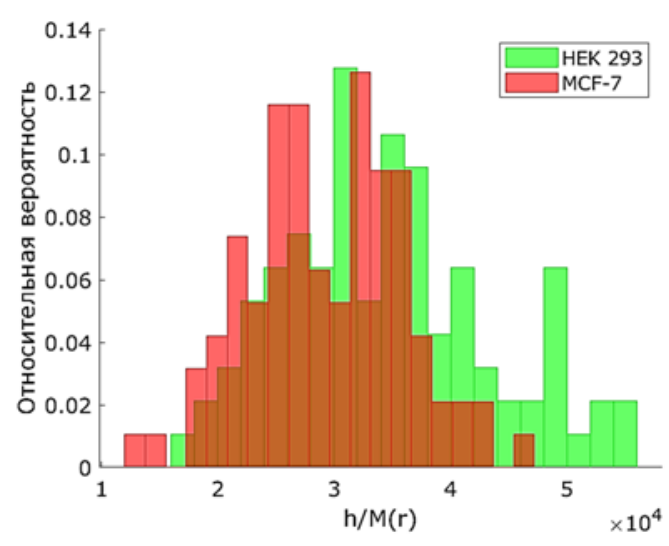

$a$

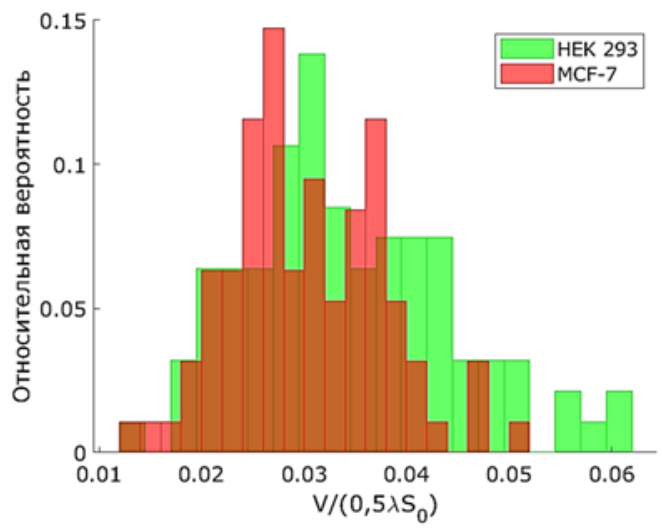

6

Puc. 14. Распределения безразмерных комплексов $h / M(r)(a), V /(0,5 \lambda S 0)$ (б) клеток культур MCF-7 (красный иввет) и НЕК 293 (зеленый извет)

На втором этапе проведено сравнение морфометрических показателей клеток, выделенных из одного источника - молочной железы человека: клеток злокачественной опухоли эпителиального происхождения MCF-7 и нормальных клеток MCF-10A. Установлено (рис. 15), что по всем морфометрическим показателям исследуемые выборки имеют статистически значимые различия $(p<0,001)$.

Проведена оценка парной корреляции морфометрических показателей культур MCF-7 и MCF-10A. В таблице представлены результаты оценки парных корреляций высоты фазового изображения клетки $h$, объема фазового изображения клетки $V$ и среднего радиуса фазового изображения клетки $M(r)$. Данные показатели выбраны на основе анализа распределений их относительной вероятности (рис. 16). Критерием служила малость области пересечения распределений относительной вероятности исследуемых параметров. Полученные результаты показали положительные корреляционные зависимости пар, за исключением $h-M(r)$ для культуры MCF-10A.

На основе результатов статистического и корреляционного анализа для корректного сравнения морфометрических параметров клеток MCF-7 и MCF-10A предложено использовать следующие безразмерные комплексы: $h / M(r)$ и $V /\left(0,5 \lambda S_{0}\right)$, где $S_{0}=4 / 3 \pi r^{2}$. На рис. 17 представлены гистограммы относительной ве- роятности этих комплексов. Из анализа данных распределений выведены критерии дифференциации нормальных и патологически измененных клеток, полученных из одной и той же ткани (органа), на примере раковых и нормальных клеток молочной железы человека. Критерий формулируются следующим образом. Эпителиальная клетка молочной железы человека считается нормальной, если значение $h / M(r)$ не превышает $2,2 \times 10^{4}$ и значение $V /\left(0,5 \lambda S_{0}\right)$ не превышает 0,02 , в противном случае исследуемая клетка - раковая (рис. 17).

Ранее отмечалось, что такие параметры, как периметр и объем фазового изображения могут служить критерием для оценки патологического состояния эритроцитов [12]. Имеются также данные об использовании оптической толщины клетки для обнаружения различий между раковой и нормальной клеткой молочной железы на примере 55 образцов, полученных от 11 пациентов с диагнозом «рак молочной железы» [15]. Однако данный критерий применим исключительно к клеткам молочной железы человека, так как базируется на оценке только одного параметра, который измеряется в абсолютных величинах (нм). Полученные в данном разделе критерии базируются на значениях безразмерных комплексов морфометрических показателей, что обусловливает возможность применения последних для дифференциации клеток злокаче 


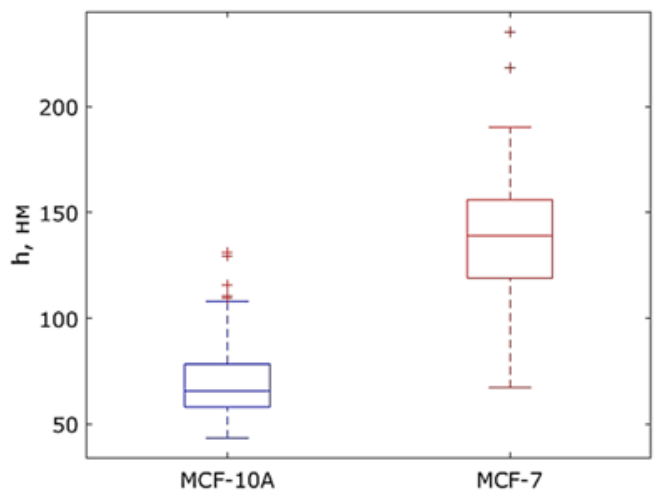

$a$
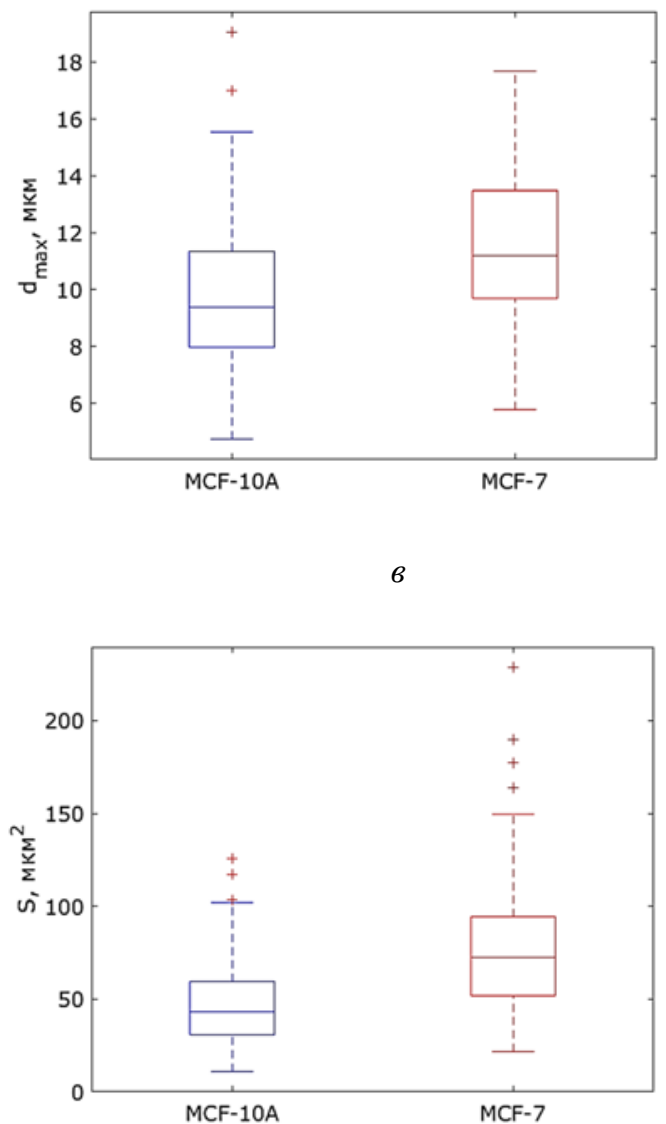

$\partial$

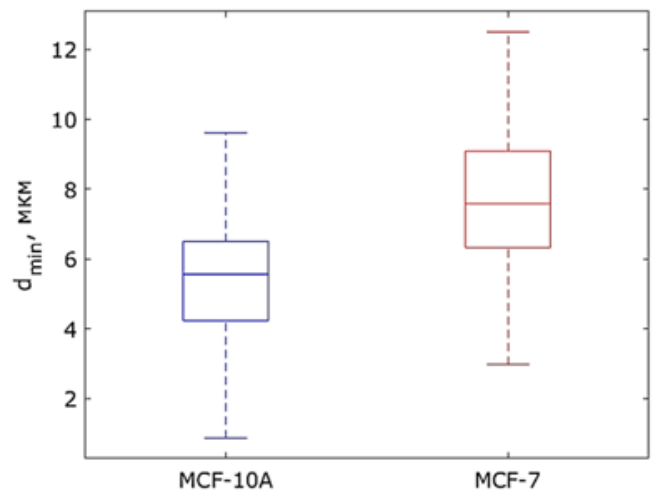

$\sigma$

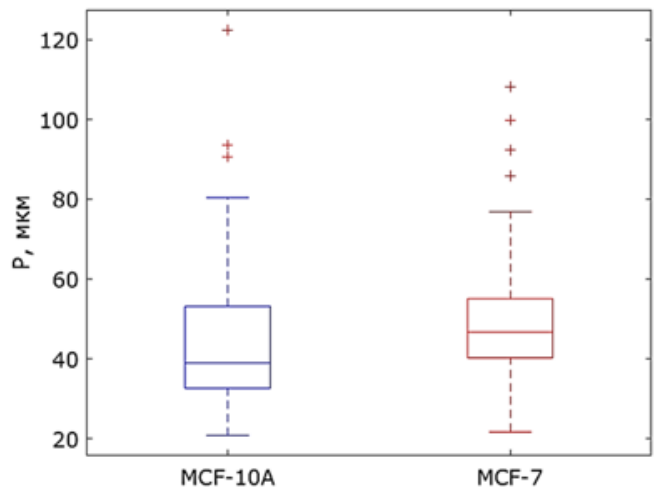

2

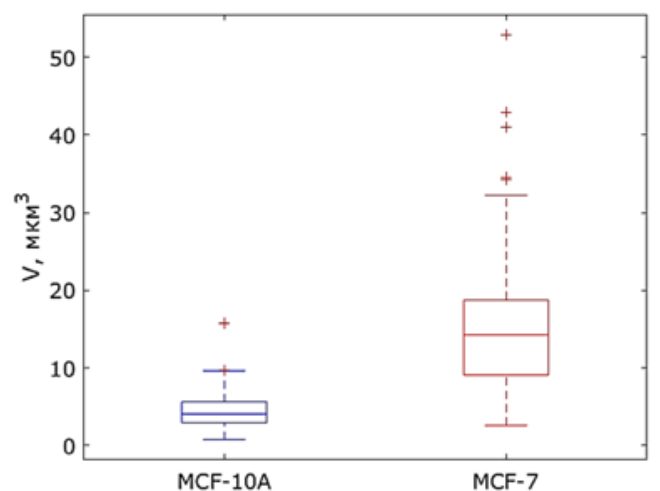

Рис. 15. Сравнение морфометрических показателей нераковых (MCF-10A) и раковых (MCF-7) клеток: сравнение высоты фазового рельефа (а); по минимальному и максимальному диаметрам фазового изображения (б, в); по периметру и площади фазового изображения (2, д); объема фазового рельефа клеток (е). Средняя горизонтальная линия - это медианное значение выборки. Верхняя и нижняя горизонтальные границы бокса - это 75\%-ная и 25\%-ная квантили соответственно. Верхний и нижний доверительные интервалы соответствуют экстремальным значениям выборки. Красные точки (+) - точки выборки, которые выходят за границы доверительных интервалов 


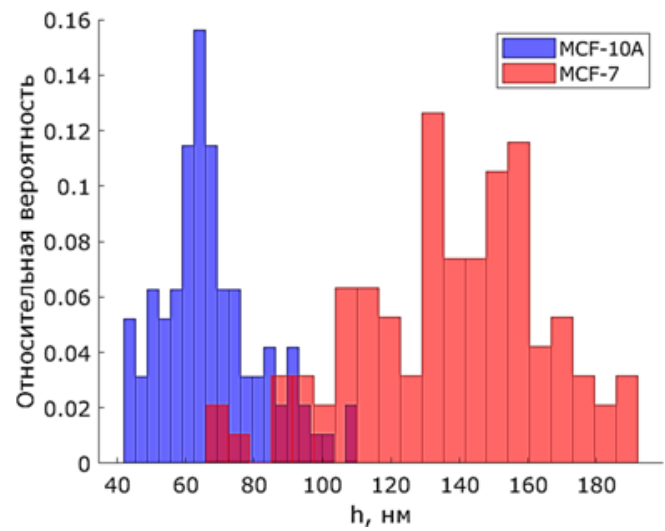

$a$
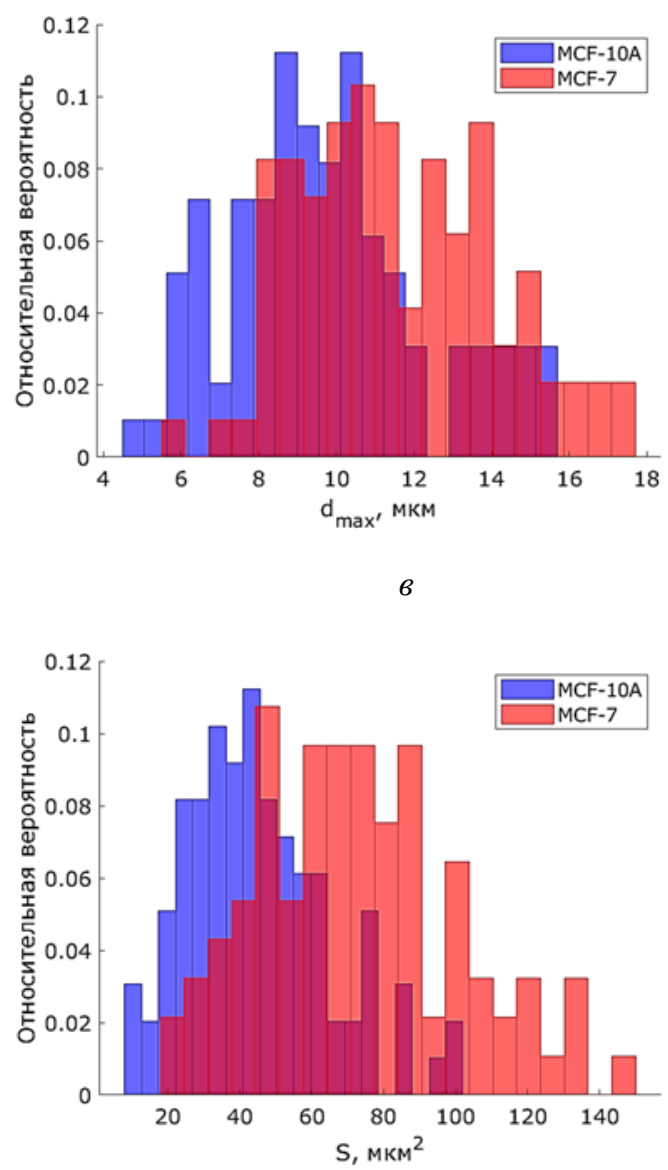

$\partial$

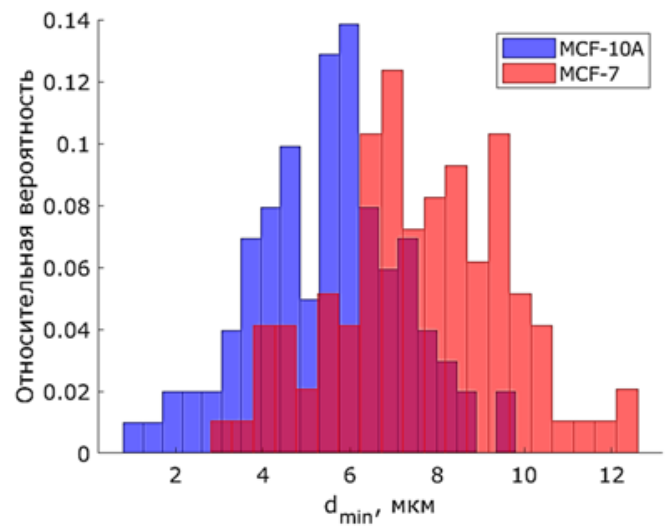

6
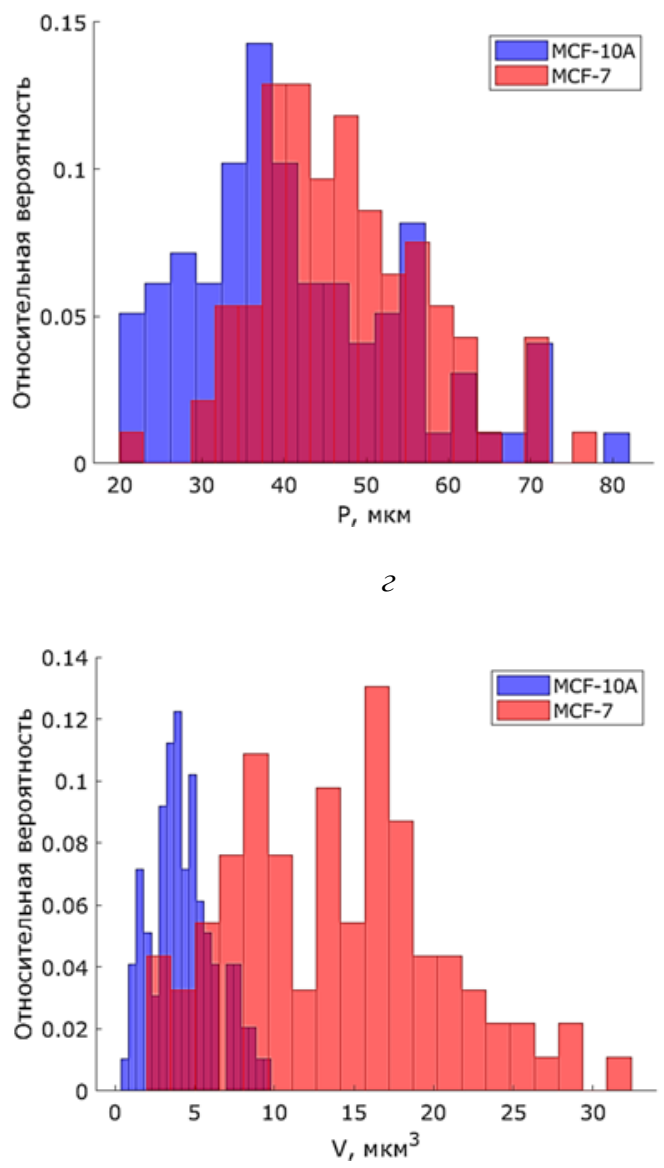

e

Рис. 16. Распределения высоть (а), минимального диаметра (б), максимального диаметра (в), периметра (2), площзади (д) и объема (е) фазовых изображений клеток культур MCF-7 (красный иявет) и МCF-10А (синий ц̧вет) 


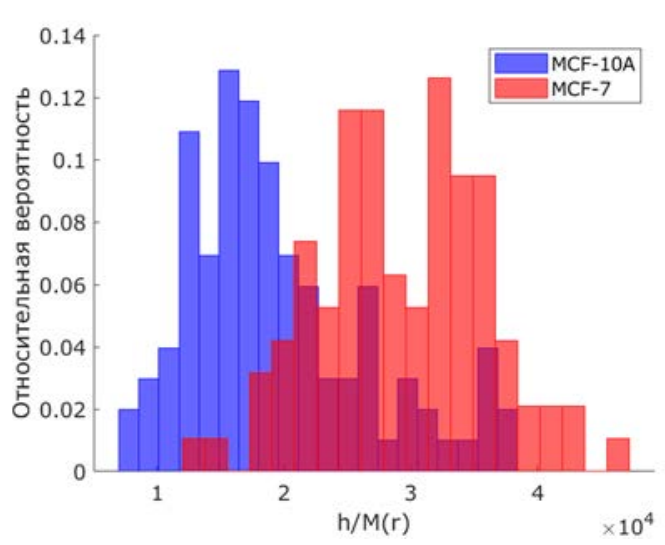

$a$

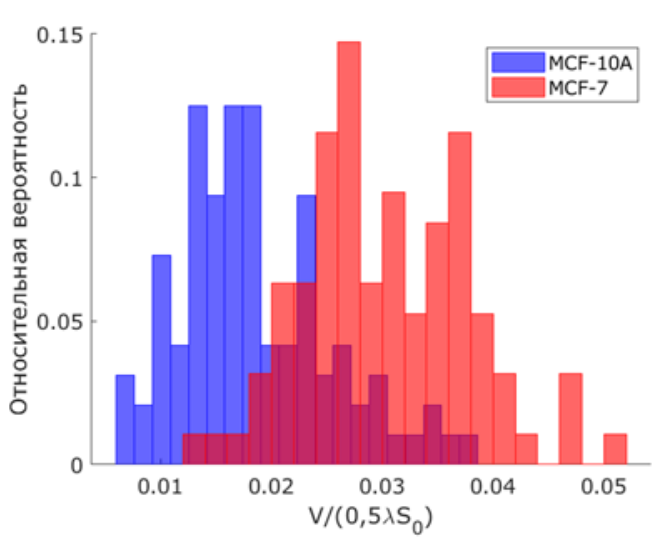

6

Рис. 17 Распределения безразмерных комплексов $h / M(r)(a), V /\left(0,5 \lambda S_{0}\right)(б)$ клеток культур MCF-7 (красный цзвет) и МCF-10A (синий иявет)

ственной опухоли эпителиального происхождения (раковых клеток). При этом исследование должно проводиться в сравнении с нормальными эпителиальными клетками из того же источника (органа, ткани), что и анализируемые раковые клетки.

\section{Заключение}

Последовательность трансформации коллективных мод - открытых комплексов при структурно-скейлинговых переходах в ДНК и клетках, позволила предложить описание дальнодействующих механизмов, инициирующих формирование фенотипов как спектра конечно-амплитудных мод бризерного типа, с последующей трансформацией последних в автосолитонные моды и диссипативные структуры обострения, обеспечивающие механизмы транскрипции, формирование хромосомных структур для реализации естественного сценария деления клеток. На основе созданных программных комплексов, реали- зующих выделение пространственно-временных сингулярных мод различной природы (конечно-амплитудных возмущений, характеризующих кинетику поврежденности клетки), обоснована методология обработки данных когерентной фазовой микроскопии для количественной дифференциации клеток «в норме» и раковых клеток, основанная на вычислении инвариантов динамического поведения системы. Проведены измерения оптической толщины раковых клеток культуры MCF-7 и нормальных клеток культур HEK 293 и MCF-10A на основе метода лазерной интерференционной микроскопии. Всего измерено порядка 300 клеток. Определены морфометрические показатели фазовых изображений клеток. Выполнен сравнительный анализ морфометрических показателей фазовых изображений раковых и нормальных клеток, на основе которого определен критерий дифференциации клеток, выделенных из одного источника (ткани, органа).

\section{Библиографический список}

1. Peyrard M. Nonlinear dymamics and statistical physics of DNA // Nonlinearity. - 2004. - Vol. 17. - № 2. P. 1-40.

2. Naimark O.B. Structural-scaling transitions and localized distortion modes in the DNA double helix // Phys. Mesomech. - 2007. - Vol. 10. - № 1-2. - P. 33-45.

3. Peyrard M., Bishop A.R. Statistical mechanics of a nonlinear model for DNA denaturation // Phys. Rev. Lett. - 1989. - Vol. 62. - P. 2755-2758.

4. Naimark O.B. Defect Induced Transitions as Mechanisms of Plasticity and Failure in Multifield Continua // Advances in Multifield Theories of Continua with Substructure, / ed. G. Capriz and P. Mariano, Birkhäuser. Boston. - 2004. - P. 75-114.

5. Naimark O.B. Structural-Scale Transitions in Solids with Defects and Symmetry Aspects of Field Theory // Phys. Mesomech. - 2010. - Vol. 13. - № 5-6. - P. 306-317.

6. Naimark O.B., Nikitiuk A.S., Baudement M.-O., Forne T., Lesne A. The physics of cancer: The role of epigenetics and chromosome conformation in cancer progression // AIP Conference Proceedings 
«International Conference on Physics of Cancer: Interdisciplinary Problems and Clinical Applications (PC'16)». - 2016. - Vol. 1760, Iss. 1. - P. 020051.

7. Tsuchiya M., Giuliani A., Hashimoto M., Erenpreisa J., Yoshikawa K. Emergent Self-Organized Criticality in gene expression dynamics: Temporal development of global phase transition revealed in a cancer cell line // PLOS ONE. - 2015. - Vol. 11. - P. 1-33.

8. Tsuchiya M., Hashimoto M., Takenaka Y., Motoike I.N., Yoshikawa K. Global genetic response in a cancer cell: Self-organized coherent expression dynamics // PLOS ONE. - 2014. - Vol. 9. - P. 1-33.

9. Naimark O.B. Mesoscopic cell dynamics in different environment and problem of cancer. (AIP Proceedings, in print).

10. Naimark O.B. Nonlinear dynamics and damage induced properties of soft matter with application in oncology //AIP Conference Proceedings «International Conference on Physics of Cancer: Interdisciplinary Problems and Clinical Applications (PC IPCA'17)». - AIP Publishing - 2017. - Vol. 1882. - № 1. - P. 020052.

11. Ignatyev P.S., Indukaev K.V., Osipov P.A. [et al.] Laser interference microscopy for nanobiotechnologies // Biomedical Engineering. - 2013. - Vol. 47. - № 1. - P. 32-35.

12. Laser interference microscopy in erythrocyte study / A.I. Yusipovich, E.Y. Parshina, N.Y. Brysgalova [et al.] //Journal of Applied Physics. - 2009. - Vol. 105. - № 10. - P. 102037.

13. Nebogatikov V., Nikitiuk A., Konysheva A., Ignatyev P., Grishko V., Naimark O. Study of morphological changes in breast cancer cells MCF-7 under the action of pro-apoptotic agents with laser modulation interference microscope MIM-340 // AIP Conference Proceedings «International Conference on Physics of Cancer: Interdisciplinary Problems and Clinical Applications (PC IPCA'17)». - 2017. - Vol. 1882, № 1. - P. 020053.

14. Canny J. A Computational approach to edge detection //IEEE Transactions on pattern analysis and machine intelligence. - 1986. - № 6. - P. 679-698.

15. Когерентная фазовая микроскопия на модели рака молочной железы / В.И. Чиссов, В.П. Тычинский, Н.Н. Волченко [и др.] // Альманах клинической медицины. - 2006. - № 12. - С. 68.

\title{
MECHANOBIOLOGICAL STUDY OF THE DYNAMICS AND MORPHOLOGY OF CELL STRUCTURES BY LASER MICROSCOPY AND APPLICATIONS IN ONCOLOGY
}

\author{
O.B. Naimark ${ }^{1}$, V.V. Grishko ${ }^{2}$, Y.V. Bayandin ${ }^{1}$, A.S. Nikityuk ${ }^{1}$ \\ ${ }^{1}$ Institute of continuous media mechanics UB RAS \\ ${ }^{2}$ Institute of technical chemistry UB RAS
}

The research is devoted to experimental and theoretical substantiation of the use of mechanobiological characteristics of cells as phenotypic markers of oncological pathologies. In the development of approaches related to the study of the mechanical state of cells in the «normal» and in the evolution of tumors, a comparative analysis has been carried out of the nonlinear dynamics of cell structures on the basis of the original data on the dynamics of "phase thicknesses» of cells obtained by coherent phase microscopy. The results of experimental studies have been generalized on the basis of epigenetic models reflecting mechanobiological features of cell and tissue structures in the development of cancer.

Keywords: cell mechanobiology, coherent phase microscopy, open complexes, nonlinear dynamics, morphometry, mono and multifractality.

\section{Сведения об авторах}

Наймарк Олег Борисович, доктор физико-математических наук, профессор, заведующий лабораторией физических основ прочности, Институт механики сплошных сред УрО РАН - филиал Пермского федерального исследовательского центра УрО РАН (ИМСС УрО РАН), 614013, ул. Академика Королева, 1; e-mail: naimark@icmm.ru

Гриико Виктория Викторовна, кандидат химических наук, доцент, заведующий лабораторией биологически активных соединений, Институт технической химии УрО РАН - филиал Пермского федерального исследовательского центра УрО РАН (ИТХ УрО РАН); e-mail: grishvic@gmail.com Баяндин Юрий Витальевич, кандидат физико-математических наук, старший научный сотрудник, ИМСС УpО РАН; e-mail: buv@icmm.ru

Никитюк Александр Сергеевич, младший научный сотрудник, ИМСС УpO PAH; e-mail: nas@icmm.ru 